\title{
Editorial
}

\section{Soldando neuronas}

Un equipo de investigación ha desarrollado un método de conectar neuronas usando pulsos de láser ultracortos, una técnica revolucionaria que abre la puerta hacia nuevas oportunidades de investigación y tratamientos en el ámbito médico, y bajo el concepto moderno de la nanoteconología. El equipo de Nir Katchinskiy, de la Universidad de Alberta en Canadá, es el primero de la historia en encontrar una forma de unir neuronas y, al hacerlo, ha proporcionado a la comunidad científica una nueva y poderosa herramienta. Katchinskiy tenía en mente una aplicación práctica específica cuando inició el proyecto: la posibilidad de reparar un nervio cortado, o más concretamente "soldar" ambos extremos. El equipo de Katchinskiy puso en contacto entre sí dos neuronas colocadas en una solución especial que evita que se peguen. En el punto de contacto entre ambas células se lanzaron pulsos de láser de una duración de femtosegundos (cada pulso ultracorto separado por entre 10 y 15 segundos). Aunque la capa exterior de ambas células se vio parcialmente comprometida, el interior de la capa protectora permaneció intacto. Como resultado de ello, las dos células establecieron conexiones sólidas, formando una membrana común en el área seleccionada. A través de múltiples experimentos, las células permanecieron viables y con una conexión fuerte. Las neuronas tardaron 15 milisegundos en unirse entre sí, un proceso que habría requerido horas de forma natural. La ventaja más grande del descubrimiento es que da a los investigadores un control completo sobre el proceso de conexión celular. Quizá no se pueda tratar la médula espinal humana con esta nueva técnica, pero nos acerca a ello, tal como matiza Abdul Elezzabi, del equipo de investigación. Hasta ahora, el equipo ha aplicado este método a tres tipos de células, pero el potencial de la técnica parece ilimitado. Evidentemente un gran avance en el campo de las neurociencias utilizado técnicas de Nanotecnología, disciplina que ya se ha comunicado en nuestros congresos y publicado en la Revista Chilena de Neurocirugía.

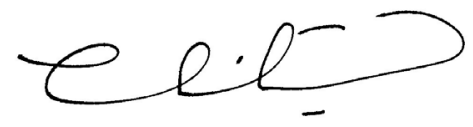

Editor Jefe

Revista Chilena de Neurocirugía 


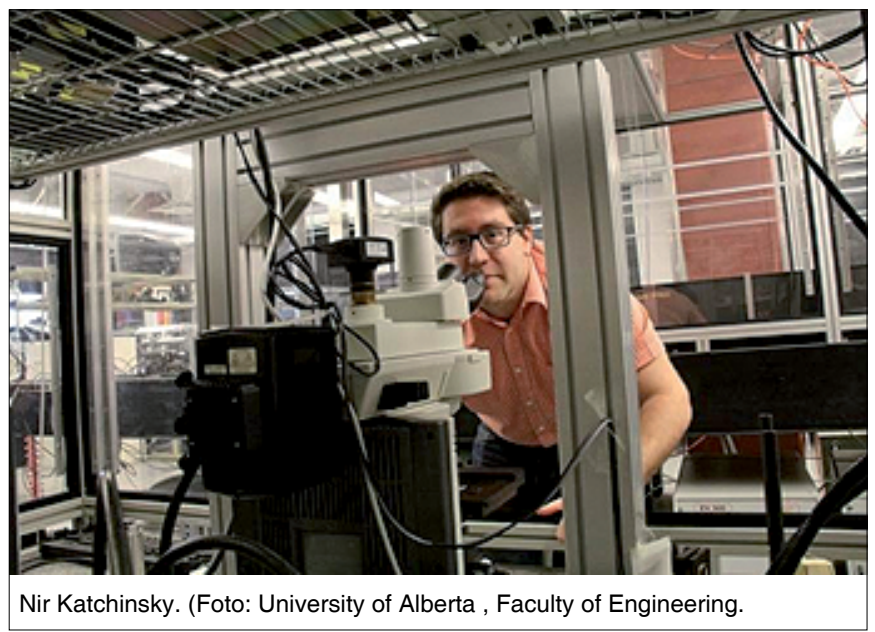

\section{Bibliografía}

Nir Katchinskiy ${ }^{1}$, Helly R. Goez ${ }^{2}$, Indrani Dutta ${ }^{3}$, Roseline Godbout ${ }^{3}$ \&Abdulhakem Y. Elezzabi'. www.nature.com/scientificreports. Scientific Reports | 6:20529 | DOI: 10.1038/srep20529 Department of Electrical and Computer Engineering, University of Alberta, Edmonton, $\mathrm{AB}$, Canada.

2 Division of Pediatric Neurology, Department of Pediatrics, Faculty of Medicine and Dentistry, University of Alberta, Edmonton, AB, Canada.

3 Department of Oncology, University of Alberta, Cross Cancer Institute, Edmonton, AB, Canada. Correspondence and requests for materials should be addressed to N.K. (email: katchins@ualberta.ca). 